\title{
Powder and Solvent for Oral Suspension Dosage Form
}

National Cancer Institute

\section{Source}

National Cancer Institute. Powder and Solvent for Oral Suspension Dosage Form. NCI

Thesaurus. Code C149790.

Powder and solvent intended for the preparation of an oral suspension by dispersing the powder in the solvent. 